CommentaRy on COVID-19 AND the Food System

\title{
A collaborative approach to COVID-19 response: The Center for Environmental Farming Systems community-based food system initiatives
}

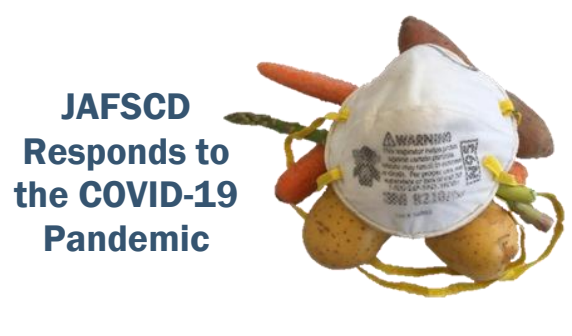

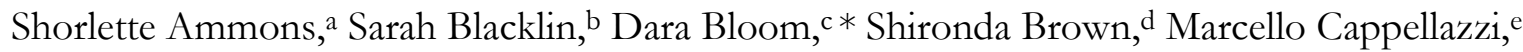

Nancy Creamer, ${ }^{\mathrm{f}}$ Angel Cruz, ${ }^{\mathrm{g}}$ Janie Hynson, ${ }^{\mathrm{h}}$ Gini Knight, ${ }^{\mathrm{i}}$ and Laura Lauffer ${ }^{\mathrm{j}}$

Center for Environmental Farming Systems (CEFS), North Carolina State University

Kathleen Liang ${ }^{\mathrm{k}}$

Center for Environmental Farming Systems (CEFS), North Carolina Agricultural and

Technical State University

Lee Menius, ${ }^{1}$ Abbey Piner, ${ }^{\mathrm{m}}$ Arneisha Smallwood, ${ }^{\mathrm{n}}$ Robyn Stout, ${ }^{\circ}$ Caroline Stover, ${ }^{\mathrm{p}}$

Tessa Thraves, ${ }^{\mathrm{q}}$ and Bevelyn Ukah ${ }^{\mathrm{r}}$

Center for Environmental Farming Systems (CEFS), North Carolina State University

Note: Authors share equal authorship and are listed alphabetically

Submitted October 2, 2020 / Published online March 16, 2021

Citation: Ammons, S., Blacklin, S., Bloom, D., Brown, S., Cappellazzi, M., Creamer, N., Cruz, A., Hynson, J., Knight, G., Lauffer, L., Liang, K., Menius, L, Piner, A., Smallwood, A., Stout, R., Stover, C., Thraves, T., \& Ukah, B. (2021). A collaborative approach to COVID-19 response: The Center for Environmental Farming Systems community-based food system initiatives. Journal of Agriculture, Food Systems, and Community Development, 10(2), 297-302. https://doi.org/10.5304/jafscd.2021.102.004

Copyright (C) 2021 by the Authors. Published by the Lyson Center for Civic Agriculture and Food Systems. Open access under CC-BY license.

\footnotetext{
Abstract

The Center for Environmental Farming Systems (CEFS) has spent the past two decades developing local food systems to support communities and increase resilience. The COVID-19 pandemic has shown how existing structural inequities, primarily along racial lines, are exacerbated. It has also shown the value of community-based food systems work that helps communities network, sharing valuable resources and

a Shorlette Ammons, Equity in Food Systems Extension Associate, Committee on Racial Equity in the Food System, CEFS, NC State University (NCSU); sammons2@ncsu.edu

b Sarah Blacklin, Program Director, NC Choices, CEFS, NCSU; sarah@,ncchoices.com

c* Corresponding author: Dara Bloom, Ph.D., Associate Professor and Local Foods Extension Specialist, Department of Agricultural and Human Sciences; CEFS Assistant Director of Community Based Food Systems; 512 Brickhaven Drive Campus Box 7606; Raleigh, NC 27695 USA; dara bloom@ncsu.edu

d Shironda Brown, Training Project Coordinator, NC Farm to Early Care and Education, CEFS, NCSU; sewilli3@,ncsu.edu MORE AUTHOR DETAILS ON NEXT PAGE
} 
funding to respond to the ongoing crisis. In this article, we document how CEFS' community-based food systems initiatives are responding to the pandemic. Some of CEFS programs are community-based, working with food policy councils, offering racial equity trainings, networking schools and early care and education sites, and supporting youth convenings and internships. Others are focused on production and supply chains for meat, seafood, and produce in order to develop stronger local food systems. Throughout the work of all of CEFS' community-based food systems initiatives in response to the pandemic, we have learned that our past efforts have increased local food systems resilience. We also note the importance of flexible funders who allowed grant dollars to be reallocated to community partners to address urgent needs. We have found that online programming has increased participation and access to resources. Finally, we have been inspired by the creativity, flexibility, and adaptability of our community partners, and we are energized to continue to support them while also offering the resources we have developed to a broader audience.

\section{Keywords}

Community, Food System, Networking, Funding, Racial Equity, COVID-19, COVID-19 Response, Pandemic, Local Food

\section{Introduction}

The Center for Environmental Farming Systems (CEFS) was established in 1994 as a partnership among North Carolina State University, North Carolina Agricultural and Technical State University, and the North Carolina Department of Agriculture and Consumer Services. CEFS develops and promotes just and equitable food and farming systems that conserve natural resources, strengthen communities, improve health outcomes, and provide economic opportunities in North Carolina (NC) and beyond.

The pandemic has disrupted the food system at key points where CEFS' initiatives work, exacerbating pre-existing inequalities and highlighting supply chain disjunctures (Alkon, Bowen, \& Kato, 2020; Anderson, 2020; Havice, Marschke, \& Vandergeest, 2020; Hendrickson, 2020). Black, Indigenous and People of Color (BIPOC) were already disproportionately affected by issues in the food system, including low-wage labor and access to healthy food (Gray, 2014; Kato, 2013). These issues have been brought into stark relief by the pandemic, both in terms of growing food insecurity rates as well as the fact that food retail workers and farm laborers are on the forefront of "essential workers" who are most exposed

\footnotetext{
e Marcello Cappellazzi, Communications Specialist, CEFS, NCSU; mcappel@ncsu.edu

${ }^{\mathrm{f}}$ Nancy Creamer, Ph.D., Distinguished Professor of Sustainable Agriculture and Community Based Food Systems, Horticulture Department; Former CEFS Co-Director, NCSU; ncreamer@ncsu.edu

g Angel Cruz, Ph.D., Academic and Extension Initiatives Manager, CEFS, NCSU; aecruz@ncsu.edu

h Janie Hynson, Communications Manager, CEFS, NCSU; itmoore8@,ncsu.edu

${ }^{\mathrm{i}}$ Gini Knight, Program Coordinator, Community Food Strategies, CEFS, NCSU; gini knight@ncsu.edu

¡ Laura Lauffer, Project Director, EmPOWERing Mountain Food Systems, CEFS, NCSU; lwlauffe@ncsu.edu

${ }^{k}$ Kathleen Liang, Ph.D., W. K. Kellogg Distinguished Professor of Sustainable Agriculture, CEFS Co-Director, North Carolina Agricultural and Technical State University; cliang@ncat.edu

${ }^{1}$ Lee Menius, Technical Program Coordinator, NC Choices, CEFS, NCSU; lamenius@ncsu.edu

m Abbey Piner, Program Director, Community Food Strategies, CEFS, NCSU; abbey piner@ncsu.edu

${ }^{n}$ Arneisha Smallwood, Outreach Assistant, Farm to School, CEFS, NCSU; ansmallw@ncsu.edu

o Robyn Stout, Statewide Coordinator, NC 10\% Campaign, CEFS, NCSU; robyn_stout@ncsu.edu

p Caroline Stover, Project Director, NC Farm to Early Care and Education, CEFS, NCSU; cmstover@ncsu.edu

qTessa Thraves, Farm to School Coordinator, CEFS, NCSU; tes thraves@ncsu.edu

${ }^{\mathrm{r}}$ Bevelyn Ukah, Youth Food Systems Coordinator, CEFS, NCSU; bevelyn ukah@,ncsu.edu
} 
to COVID-19, and as a result are disproportionately affected by the pandemic (Alkon et al., 2020). Food access for children has been affected by school and early care closures, as these sites are often the primary source of meals for children, most notably in BIPOC communities (Bowen, Brenton, \& Elliott, 2019; Poppendieck, 2011). There is also concern about how the pandemic will affect career trajectories for youth, as many professional development opportunities, such as internships for college students, have been cancelled as a result of the pandemic (Aucejo et al., 2020).

Supply chains have also been disrupted by the pandemic, once again revealing pressure points and bottlenecks that are the result of concentration in the food system (Grandin, 2020; Hendrickson, 2020). Meat shortages, accompanied by excess livestock and plummeting prices for producers, have increased demand for local meat beyond the capacity of processors. Many fisheries and produce growers lost their primary wholesale markets due to restaurant closures. While some producers have been able to pivot to online marketing platforms, others have been left behind as their markets dry up (Carolina Farm Stewardship Association [CFSA], 2020).

For CEFS, these issues hit close to home, affecting our community partners and stakeholders. We see our work to challenge systemic racism as all the more critical in this current moment, and a key component of all our programming. We also have witnessed the power of existing community networks to respond quickly in a crisis. The following is an overview of how CEFS' community-based food systems initiatives have mobilized to respond to the COVID-19 pandemic.

\section{CEFS Community-Based Food Systems Response}

\section{Community Networks and Racial Equity}

Community Food Strategies, ${ }^{1}$ which organizes and supports 36 adult and two youth food policy councils, has convened this statewide network twice a month during the pandemic for co-learning and support, and has begun monthly racial identity caucus sessions. Community Food Strategies also led a six-part online series, "Facilitating Virtually," 2 to share best practices for increasing participation, engagement, and forward movement in online meetings. In addition, Community Food Strategies has channeled US $\$ 24,500$ in micro-grants to 25 food councils ${ }^{3}$ to support immediate and long-term community-based efforts, such as hunger relief, gardens, farms, and small businesses, with an additional US $\$ 100,000^{4}$ previously scheduled to be distributed in the fall of 2020. These funds were allocated using a shared gifting ${ }^{5}$ process that gives food councils the power to decide how funding should be distributed, with an emphasis on equity.

Requests for racial equity trainings that build a deeper analysis around the impacts of structural racism on the food system have increased tremendously. CEFS' Committee on Racial Equity in the Food

\footnotetext{
${ }^{1}$ Community Food Strategies is a multi-organizational project supported by team members across seven organizations: Appalachian Sustainable Agriculture Project, Care Share Health Alliance, Carolina Farm Stewardship Association, Center for Environmental Farming Systems, Food Bank of Central and Eastern NC, Kindred Seedlings, and NC Rural Center. Community Food Strategies is funded by the W.K. Kellogg Foundation and the Blue Cross Blue Shield of North Carolina Foundation.

https://communityfoodstrategies.org

2 https://communityfoodstrategies.org/2020/03/20/facilitating-virtually/

3 These microgrants were made possible early on in the pandemic by the Blue Cross and Blue Shield of North Carolina Foundation, which, in addition to a grant supporting Community Food Strategies, made additional funding available that Community Food Strategies distributed to communities. See more at https://communityfoodstrategies.org/2020/05/20/covid-grants/

${ }^{4}$ Shared gifting funding has been provided by the Blue Cross and Blue Shield of North Carolina Foundation, the W.K. Kellogg Foundation, NC Local Food Council, Self-Help Credit Union, and the Carolina Farm Stewardship Association. https://communityfoodstrategies.org/2021/02/09/shared-gifting-resonates-2020/

${ }^{5}$ See more at https://rsfsocialfinance.org/2018/01/16/gifting-power/
} 
System (CORE) ${ }^{6}$ has increased its offerings of racial equity trainings and moved them to a virtual platform, increasing participation from 45 to 75 people per training. The goal of CORE's trainings is to create institutional change such that systems of oppression that cause crises that disproportionately affect BIPOC communities are completely and irrevocably dismantled.

\section{Schools, Early Care and Education, and Youth Programming}

CEFS' Farm to School (F2S) ${ }^{7}$ program and the Farm to School Coalition of $\mathrm{NC}^{8}$ redistributed US $\$ 72,000$ of grant funding 9 to 18 School Nutrition programs. ${ }^{10}$ Grants were used for efforts ranging from buying vegetables grown by small farmers, to funding farm infrastructure for school-run production farms that teach agriculture and supply produce locally. F2S also partnered with a local anti-racism education organization to provide a virtual five-part series on racial equity attended by 172 participants. CEFS and NC Cooperative Extension's Farm to School Working Group supported 38 county agents ${ }^{11}$ to partner with schools to distribute seed kits, planting, and activity guides along with school meals during COVID closures, reaching over 15,500 families.

The 15 community teams participating in the 2020 NC Farm to Early Care and Education ${ }^{12}$ Collaborative $^{13}$ remained connected to share strategies and resources about how to continue feeding children. Early care and education (ECE) providers in the Collaborative participated in "Learning Bursts," 14 a virtual training series that replaced in-person meetings, including topics on gardening, cooking, and racial equity. As an example of how local food systems strengthened resilience, ${ }^{15}$ one center found that having an existing relationship with a local dairy prior to the pandemic helped them to continue providing fresh milk in spite of national supply chain disruptions.

The Food Youth Initiative (FYI $)^{16,17}$ develops and implements curriculum with a racial equity lens and works to support primarily BIPOC and rural youth as they develop an analysis of justice, equity, and inclusion in food and climate systems. FYI hosted a week-long digital summer gathering, ${ }^{18}$ guiding youth and their adult mentors from across NC through an interactive curriculum on food systems and climate justice. Youth were paid stipends and received a certificate for their participation. In partnership with the North Carolina Local Food Council, ${ }^{19}$ CEFS is developing a Remote Internship to Support Enterprises for Local Foods (RISE) program ${ }^{20}$ to pair college students with producers who need to improve online marketing. Students are helping producers develop websites, social media, and e-commerce sites, enhancing economic opportunities for producers and providing professional development for youth.

\footnotetext{
${ }^{6}$ https://cefs.ncsu.edu/food-system-initiatives/food-system-committee-on-racial-equity/

${ }^{7}$ https://cefs.ncsu.edu/youth/farm-to-school/

${ }^{8}$ https://www.farmtoschoolcoalitionnc.org/

${ }^{9}$ Funded by Blue Cross and Blue Shield of North Carolina Foundation.

${ }^{10}$ https://cefs.ncsu.edu/youth/farm-to-school/covid-19-rapid-response/

11 https://localfood.ces.ncsu.edu/local-food-farm-to-school/covidseedsharing/

12 https://cefs.ncsu.edu/food-system-initiatives/nc-farm-to-early-care-and-education/

${ }^{13}$ Funded by the W.K. Kellogg Foundation.

${ }^{14}$ https://documentcloud.adobe.com/link/track?uri=urn\%3Aaaid\%3Ascds\%3AUS\%3A3a067890-2449-41d0-a686-5e55944dac03

15 http://www.farmtoschool.org/news-and-articles/preschools-farm-food-partnership-keep-kids-eating-local

16 https://cefs.ncsu.edu/youth/food-youth-initiative/

${ }^{17}$ Funded by the Triangle Community Foundation and the Alces Foundation.

18 https://cefs.ncsu.edu/fyi-2020-summer-gathering/

$19 \mathrm{http}: / / \mathrm{www} \cdot$ nclocalfoodcouncil.org/

20 http://www.nclocalfoodcouncil.org/rise-for-local-foods/
} 
Meat, Seafood, and Produce Production and Supply Chains

NC Choices (NCC), ${ }^{21}$ which supports niche meat supply chain development, worked in partnership with the NC Department of Agriculture and Consumer Services to direct US\$20,000,000 of legislative COVID-19 relief funds toward small-scale meat processing facilities. NCC is currently supporting project implementation and providing business consultation to awardees ${ }^{22}$ in addition to offering alternative processing resources and training to farmers. ${ }^{23}$ In an effort to build direct markets, NCC launched the successful MeatSuite.com online platform ${ }^{24}$ where customers can find local farms selling meat in bulk. ${ }^{25}$ Bulk meat sales are more affordable for consumers, help farmers move inventory, and circumnavigate COVID processing bottlenecks. MeatSuite received over 22,000 visits in the first few months, helping farmers secure new sales.

The NC 10\% Campaign ${ }^{26}$ is collaborating with NC Sea Grant ${ }^{27}$ to connect fisheries with local food home-delivery services by preparing fisheries for more direct-to-consumer markets and helping businesses handle these new products. Activities include helping businesses understand customer preferences; sharing resources about ordering, safely storing, and transporting seafood; and providing educational materials about different NC species and seasonality.

CEFS' Small Farm Unit ${ }^{28}$ staff used specialty vegetable production data to show small farmers in NC and beyond how to generate realistic financial projections in response to COVID-19. We also collaborated with NC Cooperative Extension agents to bring the e-commerce platform MarketMaker ${ }^{29}$ to North Carolina. MarketMaker was established with the support of the USDA to facilitate market relationships among farmers, buyers, vendors, and nonprofit organizations.

Empowering Mountain Food Systems ${ }^{30}$ (EMFS) supports local food system development in western NC. EMFS channeled US $\$ 46,390$ of emergency funding 31 to 14 farms, eight farmers markets, three aggregators, and one roadside stand for COVID-19-safe marketing equipment and key infrastructural investments, with more grants being released as new needs arise. EMFS also launched the \#ShopSafeShopLocalNC Campaign to highlight safe direct marketing outlets. Finally, EMFS restructured an apprenticeship program, with students working virtually to help farms develop their online presence and sales platforms, serving as a model for the statewide RISE program.

\section{Partnerships}

In addition to the partners mentioned above, CEFS collaborated with the University of Kentucky to contribute to the USDA's Local Food Systems Response. ${ }^{32}$ As part of this collaboration, CORE assembled a listening session with Black food systems leaders who uplifted how BIPOC communities experience crises disproportionately. In addition, CEFS and the Duke World Food Policy Center ${ }^{33}$

\footnotetext{
${ }^{21}$ https://cefs.ncsu.edu/food-system-initiatives/nc-choices/

22 Funded by Blue Cross and Blue Shield of North Carolina Foundation.

${ }^{23}$ Funded in part by NC Cooperative Extension's Niche Meat Working Group and USDA's Beginning Farmer and Rancher

Development Program.

${ }^{24}$ http://www.meatsuite.com/

${ }^{25}$ Funded by USDA's Beginning Farmer and Rancher Development Program.

${ }^{26}$ https://cefs.ncsu.edu/extension-and-outreach/nc-10-campaign/

27 https://ncseagrant.ncsu.edu/

${ }^{28}$ https://cefs.ncsu.edu/field-research/small-farm-unit/

${ }^{29}$ https://foodmarketmaker.com/

${ }^{30} \mathrm{https} / /$ cefs.ncsu.edu/food-system-initiatives/emfs-empowering-mountain-food-systems/

${ }^{31}$ Funded by the Appalachian Regional Commission.

32 https://lfscovid.localfoodeconomics.com/about/

33 https://wfpc.sanford.duke.edu/
} 
received a grant from the Blue Cross and Blue Shield of North Carolina Foundation to research the impacts of COVID-19 on the NC food system. This research will result in the North Carolina Food Resiliency Plan ${ }^{34}$ to guide funders' future food systems investments so that they address structural inequities and promote long-term sustainability.

\section{Conclusion and Recommendations}

COVID-19 has taught us many lessons. As demonstrated above, our prepandemic work to support local food systems helped to build resilience in the face of COVID-19. Flexibility from funders to repurpose grant funds toward COVID response has been key to our ability to channel funding to grassroots organizations that are demonstrating creative ways to support communities. We have also learned that virtual events can increase access and participation for those who might not have been able to travel or take time off before the pandemic struck. As we support communities financially and with resources, we have observed that the pandemic is fostering adaptive business models, innovative strategies, and flexible solutions. This lesson has also triggered a new urgency for CEFS to elevate our services and assistance to North Carolinians and beyond.

\section{References}

Alkon, A. H., Bowen, S., Kato, Y. \& Young, K. A. (2020). Unequally vulnerable: A food justice approach to racial disparities in COVID-19 cases. Agriculture and Human Values, 37, 535-536. https://doi.org/10.1007/s10460-020-10110-z

Anderson, M. D. (2020). Pandemic shows deep vulnerabilities. Agriculture and Human V alues, 37, 559-560. https://doi.org/10.1007/s10460-020-10108-7

Aucejo, E. M., French, J., Ugalde, M. P., \& Zafar, B. (2020). The impact of COVID-19 on student experiences and expectations: Evidence from a survey, Journal of Public Economics, 191, Art. 104271. https://doi.org/10.1016/j.jpubeco.2020.104271

Bowen, S., Brenton, J., \& Elliott, S. (2019). Pressure cooker: Why home cooking won't solve our problems and what we can do about it. New York: Oxford University Press.

Carolina Farm Stewardship Association. (2020). From 'scrambling' to 'devastated': The impact of COVID-19 on farms in North and South Carolina. Retrieved from https://www.carolinafarmstewards.org/wp-content/uploads/2020/06/CFSA-COVID-19-Survey-Report Final.pdf

Grandin, T. (2020, May 3). Temple Grandin: Big meat supply chains are fragile [Blog post]. Retrieved from the Forbes website: https://www.forbes.com/sites/templegrandin/2020/05/03/temple-grandin-big-meat-supply-chains-arefragile/?sh $=4 \mathrm{bb} 1849 \mathrm{c} 650 \mathrm{c}$

Gray, M. (2014). Labor and the locavore: The making of a comprehensive food ethic. Berkeley: University of California Press. https://doi.org/10.1525/9780520957060

Havice, E., Marschke, M., \& Vandergeest, P. (2020). Industrial seafood systems in the immobilizing COVID-19 moment. Agriculture and Human Values, 37, 655-656. https://doi.org/10.1007/s10460-020-10117-6

Hendrickson, M. K. (2020). Covid lays bare the brittleness of a concentrated and consolidated food system. Agriculture and Human Values, 37, 579-580. https://doi.org/10.1007/s10460-020-10092-y

Kato, Y. (2013). Not just the price of food: Challenges of an urban agriculture organization in engaging local residents. Sociological Inquiry, 83(3), 369-391. https://doi.org/10.1111/soin.12008

Poppendieck, J. (2011). Free for all: Fixing school food in America. Berkeley: University of California Press. https://doi.org/10.1525/9780520944411

${ }^{34}$ https://cefs.ncsu.edu/food-system-initiatives/nc-food-resiliency-plan/ 